\title{
Impacts of extreme heat on emergency medical service calls in King County, Washington, 2007-2012: relative risk and time series analyses of basic and advanced life support
}

\author{
Miriam M. Calkins ${ }^{1 *}$, Tania Busch Isaksen ${ }^{1}$, Benjamin A. Stubbs², Michael G. Yost ${ }^{1}$ and Richard A. Fenske
}

\begin{abstract}
Background: Exposure to excessive heat kills more people than any other weather-related phenomenon, aggravates chronic diseases, and causes direct heat illness. Strong associations between extreme heat and health have been identified through increased mortality and hospitalizations and there is growing evidence demonstrating increased emergency department visits and demand for emergency medical services (EMS). The purpose of this study is to build on an existing regional assessment of mortality and hospitalizations by analyzing EMS demand associated with extreme heat, using calls as a health metric, in King County, Washington (WA), for a 6-year period.
\end{abstract}

Methods: Relative-risk and time series analyses were used to characterize the association between heat and EMS calls for May 1 through September 30 of each year for 2007-2012. Two EMS categories, basic life support (BLS) and advanced life support (ALS), were analyzed for the effects of heat on health outcomes and transportation volume, stratified by age. Extreme heat was model-derived as the 95 th $\left(29.7^{\circ} \mathrm{C}\right)$ and 99 th $\left(36.7^{\circ} \mathrm{C}\right)$ percentile of average county-wide maximum daily humidex for BLS and ALS calls respectively.

Results: Relative-risk analyses revealed an 8 \% (95 \% Cl: 6-9 \%) increase in BLS calls, and a $14 \%$ (95 \% Cl: 9-20 \%) increase in ALS calls, on a heat day $\left(29.7\right.$ and $36.7^{\circ} \mathrm{C}$ humidex, respectively) versus a non-heat day for all ages, all causes. Time series analyses found a $6.6 \%$ increase in BLS calls, and a $3.8 \%$ increase in ALS calls, per unit-humidex increase above the optimum threshold, 40.7 and $39.7^{\circ} \mathrm{C}$ humidex respectively. Increases in "no" and "any" transportation were found in both relative risk and time series analyses. Analysis by age category identified significant results for all age groups, with the 15-44 and 45-64 year old age groups showing some of the highest and most frequent increases across health conditions. Multiple specific health conditions were associated with increased risk of an EMS call including abdominal/genito-urinary, alcohol/drug, anaphylaxis/allergy, cardiovascular, metabolic/endocrine, diabetes, neurological, heat illness and dehydration, and psychological conditions.

Conclusions: Extreme heat increases the risk of EMS calls in King County, WA, with effects demonstrated in relatively younger populations and more health conditions than those identified in previous analyses.

Keywords: Extreme heat, Climate change, Emergency medical services, Ambulance, Relative risk, Time series

\footnotetext{
* Correspondence: miriac@uw.edu

${ }^{1}$ Department of Environmental and Occupational Health Sciences, School of Public Health, University of Washington, 1959 NE Pacific St., P.O. Box 237234, Seattle, WA 98195, USA

Full list of author information is available at the end of the article
} 


\section{Background}

According to the Centers for Disease Control and Prevention (CDC), exposure to excessive heat kills more people than any other weather-related phenomenon, aggravates chronic diseases, and causes direct heat illness [1]. Strong associations between extreme heat and health have been identified in the literature for increased mortality [2-10] as well as hospitalizations [7, 10-13] and there is growing evidence demonstrating increased emergency department visits $[12,14,15]$ and demand for emergency medical services (EMS) [7-9, 16-24]. With high confidence in projected increases in the frequency and duration of extreme heat attributable to climate change $[25,26]$, a thorough understanding of the impacts of extreme heat on human health and the public health system is vital to efficient prevention, management, and mitigation of longterm consequences.

The existing literature describing the relationship of extreme heat and EMS calls consistently reports significant increases in risk, despite inconsistent definitions and measures of heat. Most of these studies have occurred outside the United States, including Australia [7, 8, 16], Canada [17, 18], Italy [19], Japan [20], and Switzerland [9]. Three studies have focused on U.S. cities-Boston [21], Chicago [22] and Phoenix [23]; a fourth study compared Chicago with Phoenix [24]. Many studies examined EMS dispatches for a single health condition, including heatrelated dispatch or illness $[4,18,22,24]$, pre-hospital electrocardiograms (ECG) [19], and heatstroke [20], while others only reported total call volume. Other related investigations include transportation volume [21] and identification of additional extreme heat-related factors driving EMS needs, such as hazards resulting from multisystem failures (e.g., power-outages) [27]. Overall, for all ages and causes of calls, increased risks ranged from 9 to $16 \%$ when comparing (study-specific) heat days or events to a reference heat measure $[7-9,17,21]$, with one study reporting an increased risk of $1.45 \%$ per degree Celsius increase in heat above a selected threshold [28]. Studies stratifying by age report all-cause increases in risk for groups as young as 15-64 [7, 16], however age-stratified effects for specific health conditions (excluding heat related illness) are generally reported for older age groups ( $\geq 65$ years old) $[8,9,16]$. To date, no studies have examined EMS demand for a comprehensive array of health conditions, in a tiered system where 911 dispatch centers triage calls for basic life support (BLS) and advanced life support (ALS) response teams, or in a U.S. metropolitan area with a temperate climate where projections in climate change and vulnerability risk factors may enhance the effects of extreme heat on the population.

Both individual and regional-level factors of heat vulnerability have been identified. On an individual level, age, physical fitness, and general health have been shown to affect thermoregulation of body temperature [27, 29-31], with the very young, very old, and overweight individuals at higher risk of adverse outcomes. Regionally, the Pacific Northwest is considered to be one of the more vulnerable areas of the U.S. [32] and a stronger association between temperature and mortality has been reported in northern U.S. cities than southern U.S. cities [3]. Factors contributing to differences in regional heat vulnerability include social/environmental vulnerability (e.g. poverty), social isolation, air conditioning prevalence, and the proportion of the population that is elderly or diabetic [32]. For temperate regions, such as the Pacific Northwest, disproportional warming projections associated with climate change may exacerbate regional vulnerability by increasing the frequency and severity of extreme heat more than tropical and subtropical zones [3, 25] in an area with minimal existing heat-mitigating infrastructure (e.g. air conditioning and urban design).

The effects of extreme heat on mortality and hospitalizations have been regionally characterized for King County, WA [2, 11, 33]. With a population of nearly 2.1 million, King County is the 13th most populous county in the United States [34], accounting for approximately $30 \%$ of the state's population [35]. Isaksen et al. [2] demonstrated a $10 \%$ greater, all-ages, all causes risk of death on a $99^{\text {th }}$ percentile heat day compared to a nonheat day, with risk of mortality "increasing $2.12 \%$ for each degree unit increase in humidex above $36.0^{\circ} \mathrm{C}$ ". Isaksen et al. [11] reported risks of hospitalization "increasing $1.59 \%$ for each degree increase in humidex above $37.4{ }^{\circ} \mathrm{C}$ ", but no statistically significant increases in relative risk. The purpose of our research is to build on this regional assessment by analyzing EMS demand, using calls as a health metric, associated with extreme heat. We define the primary outcome as the number of basic life support (BLS) and advanced life support (ALS) incidents dispatched by the emergency dispatch centers in King County, WA for the six year period 2007-2012. Extreme heat is defined as days exceeding a humidex value, a measure of apparent temperature, which we refer to as a "heat day" throughout this paper. The increased demand for EMS calls reported in this study captures an additional heat-health burden on the population that is not likely to be reflected in the hospitalization or mortality data.

EMS of King County is a two-tiered system offering basic life support (BLS) and advanced life support (ALS). BLS is provided by firefighters who are trained as emergency medical technicians and authorized to provide non-invasive care; the average cost of these calls is $\$ 105$ [36]. ALS is provided by paramedics who are authorized to administer more advanced patient care; the average cost of these calls $\$ 963$ (PHSKC 2012). BLS responders are always dispatched when a medical call is 
placed to local 911 call centers, but ALS responders are sent only when deemed necessary. During the period 2007-2012, approximately 30 agencies responded to 165,000 BLS calls per year, while six agencies responded to 45,000 ALS calls per year [36].

\section{Methods}

\section{EMS call and population data}

Public Health Seattle-King County's Emergency Medical Services Division provided the EMS call data with prior IRB approval from the University of Washington Human Subjects Division. We used a constrained calendar year, consisting of the 153 days occurring from May 1 through September 30 of each year, for a total of 918 days in the study period. Outcomes of interest included the patient's primary health condition requiring medical assistance, known as the patient type code, and the level of transportation required by the patient.

The patient type code describes the primary health concern identified by EMS responders during a call. EMS responders use a unique coding system to identify the most likely condition of concern based on symptoms identified in the field. This system is independent of, though similar to, the International Classification of Disease codes (ICD-9 and ICD-10) that are used in hospital and mortality settings. The patient type code categories of interest include all causes, trauma, non-trauma, subcategories of non-trauma, and specific non-trauma health conditions (Table 1). All subcategories and specific nontrauma patient-type conditions were selected a priori based on the literature $[2,7,11,33]$. Due to the nature of the EMS coding system, other variables describing the health condition of the patient were not appropriate for this analysis as they describe treatments (e.g. medication administered) or biological data (e.g. heart rate) that could be interpreted in a number of different ways. Secondary health concerns are not available in the data.

The level of transportation required by a patient was identified as either "no transportation" or "any transportation". We defined the latter as transportation by BLS, ALS, private ambulance, taxi, private automobile or any other mode of transportation to a hospital for further care. By including patient transportation in this study, we could observe additional measures of health severity, demand on EMS resources, and potential demand on emergency department (ED) resources.

A priori, we anticipated that several individual level characteristics might modify the effect of heat on EMS calls, including age, gender, race/ethnicity, and socioeconomic status; (the last two characteristics were not available for this dataset). Age groups of 0-4, 5-14, 15-44, 45-64, 65-84, and 85+ were created, and background
Table 1 Descriptive statistics for EMS data, including number of observations (n) and percent of total (\%)

\begin{tabular}{lll}
\hline Variable & BLS & ALS \\
& $n(\%)$ & $n(\%)$ \\
\hline Total calls & 361,434 & 94,565 \\
Average calls per day & 394 & 103 \\
Gender & & \\
$\quad$ Male & $174,667(48)$ & $48,779(52)$ \\
$\quad$ Female & $186,767(52)$ & $45,786(48)$ \\
Age group & & \\
$\quad 0-4$ & $10,436(3)$ & $2,141(2)$ \\
$5-14$ & $11,414(3)$ & $1,654(2)$ \\
$15-44$ & $116,587(32)$ & $23,194(25)$ \\
$45-64$ & $9,887(27)$ & $30,426(32)$ \\
$65-84$ & $80,221(22)$ & $25,407(27)$ \\
$85+$ & $43,899(12)$ & $11,743(12)$
\end{tabular}

Patient type

$\begin{array}{lll}\text { Trauma } & 47,005(13) & 6,127(6.5)\end{array}$

Non-trauma $\quad 238,045(66) \quad 82,232(87)$

Abdominal/genito-urinary $\quad 26,452 \quad 5,172$

Alcohol/drugs $\quad 17,353 \quad 4,253$

$\begin{array}{lll}\text { Anaphylaxis/allergic reaction } & 3,515 & 1,145\end{array}$

$\begin{array}{ll}\text { Cardiovascular } \quad 30,259 & 24,130\end{array}$

$\begin{array}{lll}\text { Metabolic/endocrine } & 9,439 & 4,286\end{array}$

Diabetes $\quad 3,075$

$\begin{array}{lll}\text { Neurological } & 47,986 & 13,551\end{array}$

$\begin{array}{lll}\text { Suspected CVA } & 6,432 & 1,354\end{array}$

Suspected TIA 694

$\begin{array}{lll}\text { Seizures } & 10,956 & 3,827\end{array}$

$\begin{array}{lll}\text { Febrile seizures } & 1,037 & 289\end{array}$

OBGYN 2,854 992

Other medical $\quad 58,164 \quad 14,324$

Heat illness \& dehydration $\quad 3,400 \quad 514$

$\begin{array}{ll}\text { Psychological } & 18,149\end{array}$

$\begin{array}{lll}\text { Respiratory } & 23,874 & 11,112\end{array}$

$\begin{array}{ll}\text { Asthma } & 1,130\end{array}$

Emphysema/COPD $812 \quad 580$

Not specified $\quad 76,384(21) \quad 6,206(6.5)$

Level of transportation $\quad 354526 \quad 93608$

No transportation $\quad 87,174(25) \quad 12,016(13)$

Any transportation $\quad 267,352(75) \quad 81,592(87)$

CVA cerebrovascular accident, TIA transient-ischemic attack, OBGYN obstetrics/ gynecology, COPD chronic obstructive pulmonary disease

population data were obtained from Washington's Office of Financial Management [37, 38] for each age group. Calls without recorded age or gender data were excluded from the analysis. 


\section{Meteorological-model data}

The meteorological data used in this study were produced by the University of Washington's Climate Impacts Group on the basis of the Parameter-elevation Regressions on Independent Slopes Model (PRISM) [39]. This model generated data on a grid with $\sim 1 / 16$ th resolution $(4.0 \mathrm{~km} \times$ $7.5 \mathrm{~km}$ ) using climate data from the National Oceanic and Atmospheric Administration's Global Historical Climatology Network-Daily (GHCN-Daily) database [40] and knowledge of spatially relevant geographic patterns for the Pacific Northwest [41]. Each grid center contained daily values for historic temperature (minimum/maximum), humidity, and precipitation (see Isaksen et al. $[2,11]$ for further explanation of the meteorological models).

\section{Exposure assessment}

Heat exposure was quantified as the average countywide maximum daily humidex (expressed as ${ }^{\circ} \mathrm{C}$ ). Humidex has been used as a measure of apparent temperature $[2,11,33]$ and supported as an effective predictor of heat stress [42]. To calculate this heat metric, humidex was first calculated for each grid center point using the equation below (Eq. 1), the daily maximum temperature, and average relative humidity, before being averaged across King County.

$$
\begin{aligned}
f(T, H) & =T+(5 / 9) \times(v-10), \\
\nu & =\left(6.112 \times 10^{[7.5 T / 237.7+T]}\right) \times H / 100,
\end{aligned}
$$

where $\mathrm{T}$ is the air temperature $\left({ }^{\circ} \mathrm{C}\right), \mathrm{H}$ is the humidity (\%), and $\mathrm{v}$ is the vapor pressure [43]. When compared to the dry bulb temperature in King County, a region with moderate to high relative humidity, the humidex value tends to extend the extremes to reflect a higher apparent temperature on hot days and a lower apparent temperature on cooler days than the than dry temperature (Table 2).

\section{Relative-risk analysis}

Extreme heat can be defined either as a threshold temperature chosen a priori or as a percentile of previously recorded temperatures for a specific study region. Since the latter definition is generally preferred to allow for location-specific variation of effects [44], we explored the 90th, 95th, and 99th percentile of full-year humidex values and chose the model that resulted in the maximum likelihood of fit with our data for this study based on the Akaike Information Criterion (AIC) $[5,6,33]$. Days with average maximum humidex values at or above the threshold were defined as heat days; days with values below the threshold were defined as non-heat days. The relative risk of an EMS call on a heat day compared with a non-heat day was analyzed using Poisson regression and controlled for annual variation in King County's population $[3,8]$. The relative risk model equation (Eq. 2) is as follows:

$$
\log \left(\mu_{j} / \text { population }\right)=\beta_{0}+\beta_{1} I_{j}\{\text { humidex }>\text { threshold }\}
$$

Where $j$ indexes the day, $\mu_{j}$ is the expected call count on day $j$, and $I_{j}$ \{humidex $>$ threshold $\}$ is the indicator of a heat day, defined by its countywide average humidex exceeding a threshold.

\section{Time series analysis}

We used a time series analysis to define the relationship between the intensity of heat and EMS call volume per unit increase in humidex. The analysis uses a nonparametric spline to model changes in call volume not associated with heat and a piecewise linear fit to estimate the effect of heat on calls (see Isaksen et al. $[2,11]$ for further explanation of this approach). The piecewise linear fit is set with two knots: one at the 50th percentile and one at the optimum alert threshold. That threshold was

Table 2 Meteorological descriptive data, 2007-2012

$\left.\begin{array}{lll}\hline \text { Meteorological data, May-September } & \begin{array}{l}\text { Average county-wide maximum } \\ \text { humidex }\left({ }^{\circ} \mathrm{C}\left({ }^{\circ} \mathrm{F}\right)\right)\end{array} & \begin{array}{l}\text { Average county-wide maximum dry bulb } \\ \text { temperature }\left({ }^{\circ} \mathrm{C}\left({ }^{\circ} \mathrm{F}\right)\right)\end{array} \\ \text { Minimum } & 5.9(42.6) & 7.1(44.8) \\ \text { Median } & 21.6(70.9) & 19.1(66.4) \\ \text { Maximum } & 44.7(112.5) & 34.6(94.3) \\ \text { Meteorological data, full year } & \text { Average county-wide maximum } & \text { Heat days } \geq \text { threshold }(n(\% \text { of total days in } \\ & \text { humidex }\left({ }^{\circ} \mathrm{C}\left({ }^{\circ} \mathrm{F}\right)\right) & \text { study timeframe) }\end{array}\right)$


located by increasing the model threshold by increments of $0.1^{\circ}$ between 25.0 and $44.7{ }^{\circ} \mathrm{C}$ humidex (the maximum humidex within the study time frame). Selection of the optimum alert threshold was based on the AIC selected, maximum likelihood of the best fit of the model. Heat intensity effects on EMS calls were estimated as the percent increase in daily EMS calls associated with a one-unit humidex increase above the optimum threshold. The time series model equation (Eq. 3) is as follows:

$$
\begin{aligned}
Y_{j} \sim \operatorname{Poisson}\left(P_{j} \mu_{j}\right) \text {, with } \log \left(\mu_{j}\right)=\beta_{0} & +\beta_{1}\left(h_{j}-h_{q 50}\right)_{+}+\beta_{2}\left(h_{j}-\hat{h}_{0}\right)_{+} \\
& +s\left(t_{j}\right)+\Sigma^{9}{ }_{l=6} \beta_{l} I_{\{\text {monthj }=l\}}
\end{aligned}
$$

Where $Y_{j}$ is the observed EMS call count on day $j$, $P_{j}$ is the population on day $j, \mathrm{~h}_{\mathrm{j}}$ is the county-wide average daily maximum humidex value on day $\mathrm{j}, \mathrm{h}_{\mathrm{q} 50}$ is the $50^{\text {th }}$ percentile of Humidex from January 2007 through December 2012, $\mathrm{h}_{0}$ is the optimal alert threshold, $s\left(t_{j}\right)$ is the natural cubic spline modeling the overall trend of calls over 6 years, $\left(\beta_{l}\right.$ 's) is a fixed effects adjustment for seasonal monthly effects, $s(\mathrm{t} j)$ is the natural cubic spline modeling the overall trend of EMS calls over 6 years, and $I_{\text {month }}$ is the indicator variable for months May through September.

\section{Risk-modification factors}

Two characteristics of extreme heat were hypothesized to modify the risk of an EMS call: the duration of the extreme heat [13] and the extent of the decrease in (or cooling of) the humidex overnight [45]. Duration was defined as a heat day's position in a consecutive series of heat days; increased duration was expected to augment the effects on EMS demand. The cool-down effect was defined as the difference between average county-wide high and low humidex values for any given day above the threshold. The impact of extreme heat on health was anticipated to increase with decreasing differences between high and low humidex values as a result of this effect. Impacts of these characteristics were assessed in both the relative-risk and time series analyses.

All analyses used Oracle's MySQL Workbench 5.2.47 CE [46] for data storage, RStudio [47] version 0.97.449 for data analysis, and Microsoft Excel [48] for table output.

\section{Results}

Exclusion of calls with unrecorded age and gender data reduced total call counts from 441,119 to 361,434 in the BLS data and 121,974 to 94,565 in the ALS data, resulting in an average number of calls per day of 394 for BLS and 103 for ALS (Table 1). A sensitivity analysis for excluding calls with unrecorded age and gender data demonstrated that the exclusion did not significantly impact the EMS demand for all ages and all causes (twosided $p$-value of 0.99 ). This reduction in total call counts did, however, reduce some already small sample sizes in some age and specific non-trauma categories to fewer than 20 calls on all heat days combined.

\section{Relative-risk analysis}

The analysis of BLS data, representing all calls within King County, defined extreme heat as the 95th percentile $\left(29.7^{\circ} \mathrm{C}\right)$ of humidex, while the analysis of ALS data, representing a subset of more severe calls, defined extreme heat as the 99th percentile $\left(36.7^{\circ} \mathrm{C}\right)$. Of the 918 days studied, 110 fell at or above the 95th percentile and 23 fell at or above the 99th percentile (Table 2).

Using these cutoffs, the risk of an EMS call on a heat day compared with a non-heat day increased for all causes, all ages, in both the BLS and ALS analyses (Fig. 1). The magnitude of this increase was greater for ALS (14\%, 117 vs. 103 average calls on heat days compared with non-heat days) than BLS (8 \%, 420 vs. 390 average calls on heat days compared with non-heat days). Statistically significant increases in risks for all ages were also identified in both analyses for non-trauma calls, but only the BLS analysis identified increased risk of calls for trauma. For the subcategories of non-trauma-related calls, the allages analysis identified statistically significant increases in risk in the BLS and ALS datasets for abdominal/ genito-urinary (4 \% BLS, $95 \%$ CI: 0-8 \%; $23 \%$ ALS, $95 \%$ CI: 5-45 \%), neurological (3, $95 \%$ CI: 0-6 \%; 12, 95 \% CI: 12-25\%), "other medical" (17, 95 \% CI: 13-20\%; 39, $95 \%$ CI: 25-53\%), and heat illness and dehydration (243, 95 \% CI: 207-284 \%; 607, 95 \% CI: 438-830\%) calls on a heat day compared with a non-heat day (Tables 3 and 4). The BLS analysis also revealed statistically significant increases in risk for alcohol/drug (8, 95 \% CI: 3-14 \%), anaphylaxis/allergy reaction (14, $95 \% \mathrm{CI}: 2-27 \%)$, metabolic/endocrine (11, $95 \%$ CI: 4-18\%), and diabetes (8, $95 \%$ CI: $1-$ $16 \%)$ related calls. Gender was not found to affect the relationship.

Analysis of subcategories of health effects by age showed statistically significant increased risks for heat illness and dehydration, as well as "other medical", in nearly all age groups, for both datasets (Tables 3 and 4). The 15-44 and 45-64 year-old age groups experienced a statistically significant increased risk of calls for the greatest number of different types of health conditions in both the ALS and BLS analyses. Additionally, at least one age group was identified to be at a statistically significant increased risk of a call due to abdominal/ genito-urinary (45-64 and 85+ year-old age groups in BLS and ALS, respectively) or neurological (15-44 year-old age group) concerns. The BLS analysis also identified statistically significant increased risks of calls for 


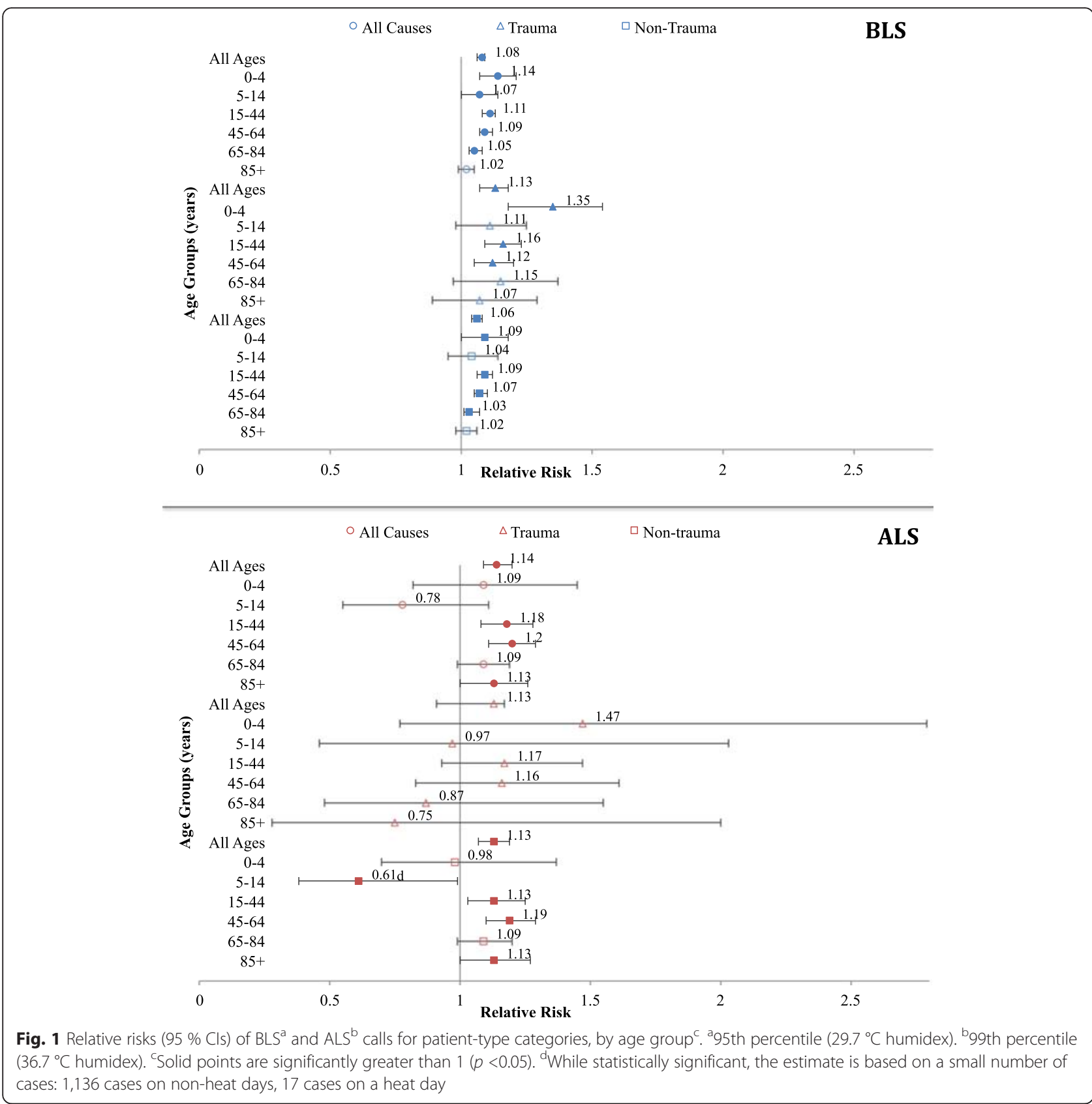

alcohol/drug (45-64 year-old age group), anaphylaxis/ allergy reaction (45-64 year-old age group), metabolic/ endocrine (45-63, 65-84, and 85+ year-old age groups), diabetes (45-64 and 65-84 year-old age group), and psychological (15-44 year-old age group) while the ALS analysis identified statistically significant increased risks of calls for cardiovascular (15-44 year-old age group) and suspected TIA (15-44 and 54-64 year old age groups), although the latter was based on small sample sizes. Relative small sample sizes are largely responsible for many of the wide confidence intervals in the ALS results for age group and subcategory of health effect. Effect estimates seen in the ALS data tended to be slightly higher than in the BLS data.

Decreased risks were detected in the BLS data for suspected TIA for all ages and for the $85+$ age group, as well as for COPD for the $85+$ age group. The ALS analysis identified decreased risks in the 5-14 year-old age group for non-trauma and neurological health effects. All decreased risks were based on small sample sizes (fewer than 20 calls on heat days), except suspected TIA for the all-ages group. Additionally, no association was found for either the $0-4$ year-old age group in the ALS analysis or for the all-ages group in either analysis 
Table 3 Relative risks (95\% Cls) for BLS ${ }^{a}$ data by age group and health condition*

\begin{tabular}{|c|c|c|c|c|c|c|c|}
\hline \multirow[t]{2}{*}{ Patient type } & \multirow[t]{2}{*}{ All ages } & \multicolumn{6}{|c|}{ Age groups (years) } \\
\hline & & $0-4$ & $5-14$ & $15-44$ & $45-64$ & $65-84$ & $85+$ \\
\hline All causes & $1.08(1.06,1.09)$ & $1.14(1.07,1.21)$ & $1.07(1,1.14)$ & $1.11(1.08,1.13)$ & $1.09(1.07,1.12)$ & $1.05(1.03,1.08)$ & $1.02(0.99,1.05)$ \\
\hline Trauma & $1.13(1.07,1.18)$ & $1.35(1.18,1.54)$ & $1.11(0.98,1.25)$ & $1.16(1.09,1.23)$ & $1.12(1.05,1.2)$ & $1.15(0.97,1.37)$ & $1.07(0.89,1.29)$ \\
\hline Non-Trauma & $1.06(1.04,1.08)$ & $1.09(1,1.18)$ & $1.04(0.95,1.14)$ & $1.09(1.06,1.12)$ & $1.07(1.05,1.1)$ & $1.03(1.01,1.07)$ & $1.02(0.98,1.06)$ \\
\hline $\begin{array}{l}\text { Abdominal/ } \\
\text { Genito-Urinary }\end{array}$ & $1.04(1,1.08)$ & $1.15(0.81,1.64)$ & $1.25(0.96,1.62)$ & $1.04(0.98,1.11)$ & $1.07(1,1.14)$ & $0.98(0.9,1.07)$ & $1.02(0.91,1.14)$ \\
\hline Alcohol/Drugs & $1.08(1.03,1.14)$ & $1.11(0.82,1.51)$ & $1.07(0.74,1.54)$ & $1.06(0.99,1.13)$ & $1.13(1.04,1.23)$ & $1.01(0.84,1.2)$ & $1.19(0.84,1.69)$ \\
\hline Anaphylaxis/Allergy & $1.14(1.02,1.27)$ & $1.29(0.96,1.73)$ & $0.93(0.67,1.28)$ & $1.07(0.9,1.26)$ & $1.23(1.01,1.51)$ & $1.24(09.4,1.63)$ & $1.12(0.71,1.71)$ \\
\hline Cardiovascular & $0.97(0.93,1.01)$ & $1.61(0.92,2.83)$ & $0.45(0.19,1.1)$ & $0.99(0.88,1.1)$ & $1.03(0.97,1.1)$ & $0.93(0.87,0.99)$ & $0.93(0.85,1.02)$ \\
\hline Metabolic/Endocrine & $1.11(1.04,1.18)$ & $1.23(0.47,3.19)$ & $1.2(0.6,2.44)$ & $0.98(0.86,1.11)$ & $1.15(1.04,1.27)$ & $1.18(1.05,1.32)$ & $1.12(1.05,1.19)$ \\
\hline Diabetes & $1.08(1.01,1.16)$ & $0.77(0.17,3.5)$ & $1.19(0.5,2.83)$ & $0.92(0.79,1.07)$ & $1.14(1.02,1.28)$ & $1.16(1.02,1.32)$ & $1(0.74,1.35)$ \\
\hline Neurological & $1.03(1,1.06)$ & $1(0.87,1.15)$ & $0.99(0.83,1.17)$ & $1.06(1,1.12)$ & $1.03(0.97,1.09)$ & $1.02(0.97,1.08)$ & $0.99(0.92,1.07)$ \\
\hline Suspected CVA & $0.97(0.89,1.05)$ & $0.57(0.06,4.95)$ & - & $1.2(0.85,1.71)$ & $0.94(0.8,1.12)$ & $0.97(0.86,1.1)$ & $0.96(0.83,1.11)$ \\
\hline Suspected TIA & $0.6(0.42,0.85)$ & $1(0.82,1.22)$ & $1(0.82,1.22)$ & - & $0.7(0.37,1.36)$ & $0.64(0.4,1.02)$ & $0.57(0.34,0.96)^{b}$ \\
\hline Seizures & $1.01(0.95,1.08)$ & $1.09(0.87,1.37)$ & $0.96(0.76,1.22)$ & $1.03(0.94,1.12)$ & $1.03(0.92,1.15)$ & $0.85(0.68,1.08)$ & $0.91(0.6,1.37)$ \\
\hline Febrile Seizures & $0.96(0.8,1.15)$ & $0.96(0.79,1.16)$ & $1.2(0.55,2.6)$ & $0.67(0.16,2.79)$ & $1.64(0.56,4.76)$ & $1.48(0.17,12.76)$ & $0.35(0.05,2.58)$ \\
\hline OBGYN & $1.06(0.95,1.19)$ & $0.87(0.29,2.59)$ & $0.67(0.07,6.04)$ & $1.07(0.95,1.2)$ & $1.15(0.65,2.02)$ & $0.53(0.12,2.38)$ & $0.95(0.37,2.41)$ \\
\hline Other Medical & $1.17(1.13,1.2)$ & $1.22(1.05,1.42)$ & $1.26(1.06,1.49)$ & $1.24(1.18,1.31)$ & $1.14(1.09,1.2)$ & $1.16(1.1,1.21)$ & $1.12(1.05,1.19)$ \\
\hline $\begin{array}{l}\text { Heat Illness \& } \\
\text { Dehydration }\end{array}$ & $3.43(3.07,3.84)$ & $3.89(2.08,7.29)$ & $4.22(2.67,6.69)$ & $4.41(3.65,5.32)$ & $4.09(3.39,4.93)$ & $2.91(2.52,3.37)$ & $2.63(2.19,3.15)$ \\
\hline Psychological & $1.03(0.98,1.08)$ & $1.68(0.78,3.6)$ & $0.99(0.72,1.34)$ & $1.07(1.01,1.14)$ & $0.99(0.91,1.08)$ & $0.93(0.8,1.07)$ & $0.84(0.64,1.1)$ \\
\hline Respiratory & $0.99(0.95,1.04)$ & $0.95(0.81,1.12)$ & $0.77(0.45,1.32)$ & $0.86(0.68,1.09)$ & $1.01(0.94,1.09)$ & $1.08(0.92,1.25)$ & $1.06(0.86,1.31)$ \\
\hline Asthma & $1.02(0.85,1.23)$ & $1.42(0.84,2.41)$ & $0.77(0.44,1.33)$ & $1.1(0.83,1.46)$ & $0.84(0.56,1.25)$ & $1.09(0.66,1.8)$ & $1.47(0.55,3.93)$ \\
\hline Emphysema/COPD & $0.95(0.77,1.18)$ & $1(0.82,1.22)$ & - & $0.82(0.1,6.38)$ & $0.87(0.57,1.33)$ & $1.16(0.88,1.52)$ & $0.41(0.18,0.96)^{c}$ \\
\hline
\end{tabular}

*Bolded relative risk values are significantly greater than $1(p<0.05)$; - indicates too few cases available to calculate

${ }^{\mathrm{a}}$ 95th percentile $\left(29.7^{\circ} \mathrm{C}\right.$ humidex)

${ }^{b}$ While statistically significant, the estimate is based on a small number of cases [221 cases on non-heat days, 17 cases on heat days]

'While statistically significant, the estimate is based on a small number of cases [107 cases on non-heat days, 6 cases on heat days]

for cardiovascular, psychological, OBGYN, and COPD call types.

An analysis of transportation volume found an increase in no transportation (12 \% BLS, $95 \%$ CI: 9-15\%; $20 \%$ ALS, $95 \%$ CI: 7-35\%) and any transportation (6\% BLS, 95 \% CI: 5-8 \%; 14 \% ALS, 95 \% CI: 8-20\%) for the all-ages group on a heat day compared with a nonheat day. Similar findings are reported by age group (Table 5), with consistently greater increases in no transportation than any transportation.

\section{Time series analysis}

The time series Humidex temperature thresholds of extreme heat were defined as $40.7{ }^{\circ} \mathrm{C}$ for BLS (5 of 918 days) and $39.7^{\circ} \mathrm{C}$ for ALS (8 of 918 days) data on the basis of model best fit.

This study found an increase-6.6 \% (95 \% CI: 4.5$8.7 \%$ ) for BLS and $3.8 \%$ (95 \% CI: $1.09-6.5 \%$ ) for ALS-in EMS calls for each one-unit increase in humidex above the analyses' respective thresholds for all causes, all ages (Table 6). Increased risks per unit increase in humidex were also identified in all ages for nontrauma (10 \% BLS, 95 \% CI: 7.6-12.5 \%; $4.2 \%$ ALS, $95 \%$ CI: 1.3-7.1\%), other medical (23.5 \% BLS, $95 \%$ CI: 19.6-27.4 \%; 18.3 \% ALS, 95 \% CI: 12.9-23.9 \%), heat and dehydration (48.5 \% BLS, 95 \% CI: 39.957.7 \%; 48.9 \% ALS, 95 \% CI: 35.9-63.1 \%), neurological (5.9 \% BLS, 95 \% CI: 1-11.1 \%), and psychological (11.5\% BLS, $95 \%$ CI: 4.1-19.4\%), but not by gender. When stratifying by age group, we found significant increased risks of BLS calls with sufficiently large sample size (greater than 20 calls on all heat days) in all causes (0-4, $15-44,45-64,65-84$, and 85+ year-old age groups), nontrauma $(5-14,15-44,65-84$, and $85+$ year-old age groups), neurological (45-64 year-old age group), other medical and heat and dehydration $(15-44,45-64,65-84$, and $85+$ year-old age groups). For ALS, increased risks with sufficiently large sample size for age groups include all causes (45-64 year-old age group) and other medical (15-44, 45-64, and 65-84 year-old age groups). Subcategories of patient-type conditions were also associated with increased risk in BLS and ALS data stratified by age, 
Table 4 Relative risks (95\% Cls) for ALS ${ }^{a}$ data by age group and health condition*

\begin{tabular}{|c|c|c|c|c|c|c|c|}
\hline \multirow[t]{2}{*}{ Patient type } & \multirow[t]{2}{*}{ All ages } & \multicolumn{6}{|l|}{ Years } \\
\hline & & $0-4$ & $5-14$ & $15-44$ & $45-64$ & $65-84$ & $85+$ \\
\hline All causes & $1.14(1.09,1.2)$ & $1.09(0.82,1.45)$ & $0.78(0.55,1.11)$ & $1.18(1.08,1.28)$ & $1.2(1.11,1.29)$ & $1.09(0.99,1.19)$ & $1.13(1,1.26)$ \\
\hline Trauma & $1.13(0.91,1.17)$ & $1.47(0.77,2.79)$ & $0.97(0.46,2.03)$ & $1.17(0.93,1.47)$ & $1.16(0.83,1.61)$ & $0.87(0.48,1.55)$ & $0.75(0.28,2)$ \\
\hline Non-Trauma & $1.13(1.07,1.19)$ & $0.98(0.7,1.37)$ & $0.61(0.38,0.99)^{b}$ & $1.13(1.03,1.25)$ & $1.19(1.1,1.29)$ & $1.09(0.99,1.2)$ & $1.13(1,1.27)$ \\
\hline $\begin{array}{l}\text { Abdominal/ } \\
\text { Genito-Urinary }\end{array}$ & $1.23(1.05,1.45)$ & $1.77(0.23,13.93)$ & $1.51(0.21,10.81)$ & $1.2(0.82,1.75)$ & $1.05(0.8,1.38)$ & $1.3(0.97,1.74)$ & $1.62(1.13,2.33)$ \\
\hline Alcohol/Drugs & $1.04(0.85,1.28)$ & $2.84(0.88,9.17)$ & - & $0.89(0.67,1.18)$ & $1.35(0.99,1.86)$ & $0.83(0.34,2.05)$ & $1.18(0.28,5.06)$ \\
\hline Anaphylaxis/Allergy & $1.06(0.73,1.54)$ & $0.71(0.17,3.04)$ & $0.7(0.18,2.73)$ & $1.35(0.81,2.24)$ & $1.16(0.58,2.31)$ & $0.72(0.19,2.8)$ & - \\
\hline Cardiovascular & $1.02(0.93,1.12)$ & $0.67(0.09,4.95)$ & - & $1.29(1.01,1.65)$ & $1.06(0.93,1.22)$ & $0.97(0.84,1.12)$ & $0.89(0.72,1.11)$ \\
\hline Metabolic/Endocrine & $1.14(0.94,1.39)$ & - & $1.94(0.27,14.18)$ & $1.07(0.72,1.57)$ & $1.01(0.72,1.41)$ & $1.29(0.93,1.79)$ & $1.46(0.76,2.78)$ \\
\hline Diabetes & $1.12(0.91,1.38)$ & - & - & $1.07(0.72,1.61)$ & $1.03(0.73,1.46)$ & $1.28(0.9,1.81)$ & $1.19(0.55,2.56)$ \\
\hline Neurological & $1.12(1,1.25)$ & $2.6(0.81,8.31)$ & $0.22(0.05,0.86)^{c}$ & $1.23(1,1.51)$ & $1.1(0.9,1.35)$ & $1.13(0.91,1.42)$ & $1.11(0.84,1.47)$ \\
\hline Suspected CVA & $1.27(0.93,1.74)$ & $1(0.65,1.53)$ & - & $1.66(0.4,6.96)$ & $0.92(0.44,1.93)$ & $1.22(0.73,2.03)$ & $1.61(0.95,2.73)$ \\
\hline Suspected TIA & $2.55(0.92,7.06)$ & $1(0.65,1.53)$ & $1(0.66,1.53)$ & $20(1.9,224)^{d}$ & $11.67(2.48,54.82)^{\mathrm{e}}$ & $1.32(0.19,8.97)$ & - \\
\hline Seizure & $0.99(0.8,1.23)$ & $0.81(0.36,1.83)$ & $0.3(0.08,1.2)$ & $1.21(0.9,1.63)$ & $1(0.68,1.48)$ & $0.84(0.4,1.75)$ & $0.63(0.15,3.62)$ \\
\hline Febrile Seizure & $1.01(0.47,2.18)$ & $1.19(0.55,2.57)$ & - & - & - & - & - \\
\hline OBGYN & $1.14(0.76,1.7)$ & - & - & $1.17(0.79,1.75)$ & $2.4(0.33,17.57)$ & - & - \\
\hline Other Medical & $1.39(1.25,1.53)$ & $0.97(0.43,2.22)$ & $1.16(0.45,2.99)$ & $1.15(0.9,1.48)$ & $1.48(1.27,1.73)$ & $1.42(1.19,1.69)$ & $1.45(1.14,1.86)$ \\
\hline $\begin{array}{l}\text { Heat Illness \& } \\
\text { Dehydration }\end{array}$ & $7.07(5.38,9.3)$ & $8.15(0.95,69.65)$ & $10.2(2.17,47.89)^{f}$ & $8.6(4.7,1)^{9}$ & $7.21(4.45,11.67)$ & $6.68(4.36,10)$ & $5.97(3.16,11)$ \\
\hline Psychological & $1.12(0.9,1.39)$ & $6.79(0.82,56.32)$ & $0.95(0.12,7.2)$ & $1(0.73,1.38)$ & $1.33(0.95,1.85)$ & $0.76(0.34,1.7)$ & $1.36(0.51,3.62)$ \\
\hline Respiratory & $1.03(0.91,1.17)$ & $0.84(0.44,1.61)$ & $0.78(0.34,1.79)$ & $1.08(0.79,1.47)$ & $1.19(0.96,1.47)$ & $0.9(0.72,1.13)$ & $1.09(0.81,1.47)$ \\
\hline Asthma & $1.3(0.83,2.03)$ & $2.6(0.81,8.31)$ & - & $1.59(0.84,3.04)$ & $1(0.31,3.3)$ & $1.15(0.28,4.73)$ & $1.7(0.24,12.08)$ \\
\hline $\begin{array}{l}\text { Emphysema/ } \\
\text { COPD }\end{array}$ & $1.38(0.85,2.23)$ & $1(0.65,1.53)$ & - & $5.81(0.72,47)$ & $1.31(0.54,3.18)$ & $1.38(0.74,2.6)$ & $1.13(0.27,4.82)$ \\
\hline
\end{tabular}

*Bolded relative risk values are significantly greater than $1(p<0.05)$; - indicates too few cases available to calculate

${ }^{\mathrm{a}}$ 99th percentile $\left(36.7^{\circ} \mathrm{C}\right.$ humidex)

${ }^{b}$ While statistically significant, the estimate is based on a small number of cases [1137 cases on non-heat days, 17 cases on a heat day]

'While statistically significant, the estimate is based on a small number of cases [379 cases on non-heat days, 2 cases on a heat day]

dWhile statistically significant, the estimate is based on a small number of cases [2 cases on non-heat days, 1 cases on a heat day]

eWhile statistically significant, the estimate is based on a small number of cases [7 cases on non-heat days, 2 cases on a heat day]

fWhile statistically significant, the estimate is based on a small number of cases [8 cases on non-heat days, 2 cases on a heat day]

${ }^{9}$ While statistically significant, the estimate is based on a small number of cases [71 cases on non-heat days, 15 cases on a heat day]

Table 5 Relative risks (95\% Cls) of transportation of BLS and $\mathrm{ALS}^{\mathrm{b}}$ calls*

\begin{tabular}{|c|c|c|c|c|c|c|c|}
\hline & \multirow[t]{2}{*}{ All ages } & \multicolumn{6}{|l|}{ Age groups (years) } \\
\hline & & $0-4$ & $5-14$ & $15-44$ & $45-64$ & $65-84$ & $85+$ \\
\hline \multicolumn{8}{|c|}{ No transportation } \\
\hline BLS & $1.12(1.09,1.15)$ & $1.20(1.09,1.32)$ & $1.08(0.98,1.18)$ & $1.14(1.10,1.19)$ & $1.12(1.07,1.17)$ & $1.10(1.05,1.15)$ & $1.07(1.00,1.14)$ \\
\hline ALS & $1.20(1.07,1.35)$ & $1.46(0.80,2.68)$ & $0.50(0.18,1.38)$ & $1.32(1.08,1.62)$ & $1.26(1.04,1.53)$ & $1.06(0.83,1.36)$ & $1.13(0.81,1.59)$ \\
\hline \multicolumn{8}{|c|}{ Any transportation } \\
\hline BLS & $1.06(1.05,1.08)$ & $1.11(1.02,1.20)$ & $1.05(0.97,1.14)$ & $1.09(1.06,1.12)$ & $1.08(1.05,1.10)$ & $1.04(1.01,1.07)$ & $1.00(0.97,1.04)$ \\
\hline ALS & $1.14(1.08,1.20)$ & $1.02(0.75,1.40)$ & $0.86(0.59,1.24)$ & $1.14(1.04,1.26)$ & $1.20(1.10,1.30)$ & $1.09(1.00,1.20)$ & $1.12(0.99,1.27)$ \\
\hline
\end{tabular}

*Bolded relative risks are significantly greater than $1(p<0.05)$

${ }^{\text {a }}$ 95th percentile $\left(29.7^{\circ} \mathrm{C}\right.$ humidex $)$

${ }^{b}$ 99th percentile $\left(36.7^{\circ} \mathrm{C}\right.$ humidex) 
Table 6 Increased risk (95\% Cls) per unit humidex increase above threshold for BLS ${ }^{a}$ and ALS ${ }^{b}$ analyses*

\begin{tabular}{|c|c|c|c|c|c|c|c|}
\hline & \multirow[t]{2}{*}{ All ages } & \multicolumn{6}{|l|}{ Age groups (years) } \\
\hline & & $0-4$ & $5-14$ & $15-44$ & $45-64$ & $65-84$ & $85+$ \\
\hline \multicolumn{8}{|c|}{ All causes } \\
\hline BLS & $6.6(4.5,8.7)$ & $11.6(1.7,22.4)$ & $4.7(-5.5,15.9)$ & $5.1(1.9,8.3)$ & $8.6(5.3,12.1)$ & $7.6(3.7,11.7)$ & $8.1(2.9,13.6)$ \\
\hline ALS & $3.8(1.09,6.5)$ & $4.2(-11.1,22.2)$ & $2.1(-16.8,25.2)$ & $1.9(-3,7)$ & $7.7(3.5,12.0)$ & $2.3(-2.7,7.5)$ & $3.6(-3.5,11.2)$ \\
\hline \multicolumn{8}{|c|}{ Trauma } \\
\hline BLS & $-4.3(-10.2,2.0)$ & $3.4(-17.2,29.1)$ & $14.5(-33.9,10.6)$ & $-11.5(-20,-2.6)$ & $-2.9(-13.1,8.5)$ & $4.5(-7.1,17.6)$ & $7.0(-8.1,24.7)$ \\
\hline ALS & $-6.3(-16.5,5.3)$ & $24.7(-5.8,65.2)$ & $-4.7(-44.8,64.4)$ & $-8.7(-21.9,6.7)$ & $-8.5(-28,16.3)$ & $-18.9(-51,34.0)$ & $-2.1(-45.3,75)$ \\
\hline \multicolumn{8}{|c|}{ Non-trauma } \\
\hline BLS & $10.0(7.6,12.5)$ & $-0.5(-100, \ln f)$ & $7.9(4.5,11.5)$ & $10.9(6.2,15.8)$ & $-0.5(-100, \operatorname{lnf})$ & $7.9(4.5,11.5)$ & $10.9(6.2,15.8)$ \\
\hline ALS & $4.2(1.3,7.1)$ & $-7.1(-26.1,16.9)$ & $-1.3(-24,28.2)$ & $1.7(-3.9,7.6)$ & $7.8(3.5,12.3)$ & $2.2(-2.9,7.5)$ & $4.2(-2.9,11.8)$ \\
\hline \multicolumn{8}{|c|}{ No transportation } \\
\hline BLS & $10.9(7.30,14.6)$ & $19.2(5.6,34.5)$ & $18.0(3.7,34.3)$ & $7.2(1.8,12.9)$ & $16.0(9.8,22.6)$ & $8.2(0.7,16.2)$ & $7.6(-2.4,18.7)$ \\
\hline ALS & $10.0(3.8,16.6)$ & $15.7(-15.3,57.9)$ & $10.9(-22.1,58.1)$ & $12.8(3.0,23.5)$ & $12.8(3.0,23.5)$ & $3.0(-10.6,18.5)$ & $-4.1(-24.2,21.2)$ \\
\hline \multicolumn{8}{|c|}{ Any transportation } \\
\hline BLS & $5.6(3.3,8.0)$ & $2.9(-10.2,17.8)$ & $-4.2(-17.2,11.0)$ & $3.8(0.1,7.6)$ & $6.3(2.4,10.3)$ & $7.4(3.1,11.9)$ & $8.1(2.2,14.2)$ \\
\hline ALS & $3.1(0.2,6.1)$ & $-2.1(-19.5,19.2)$ & $-1.0(-22.4,26.3)$ & $-1.3(-6.8,4.4)$ & $6.9(2.4,11.6)$ & $2.0(-3.3,7.6)$ & $4.6(-2.8,12.6)$ \\
\hline
\end{tabular}

*Bolded estimates are significantly greater than $1(p<0.05)$

${ }^{\mathrm{a}} 40.7^{\circ} \mathrm{C}$ humidex threshold

b $39.7^{\circ} \mathrm{C}$ humidex threshold

however all were based on fewer than 20 calls on heat days. The only call type resulting in a reduced risk was trauma $(-11.5 \%$, 95 \% CI: $(-20)-(-2.6))$ in the BLS $15-44$ year-old age group.

An analysis of transportation volume identified increases in both no transportation (10.9 \% BLS, 95 \% CI: 7.3$14.6 \%$; $10.0 \%$ ALS, $95 \%$ CI: $3.8-16.6 \%$ ) and any transportation (5.6 \% BLS, 95 \% CI: 3.3-8.0 \%; $3.1 \%$ ALS, $95 \%$ CI: $0.2-6.1 \%)$ for the all-ages group per degree increase in humidex above the respective optimal thresholds. Similar findings are reported for the 15-44, 45-64, and 64-85 year-old age groups (Table 6), with consistently greater increases in no transportation than any transportation.

\section{Risk-modification factors}

Analysis of the temporal characteristics of heat duration and nighttime cooling identified significant, though minimal, changes in the effect estimates for the BLS relative risk analysis only with increasing duration and increasing nighttime cooling each resulting in higher risks. The most frequent heat duration during the study timeframe was 1 day (13 occurrences), followed by 2 days (11 occurrences), with a maximum of 9 days (one occurrence in 2009). For all ages, all causes, there was an estimated change in calls of 0.01 calls per day of added duration. While this finding is statistically significant, the increase is arguably very small and possibly attributable to the observed increase in maximum daily average county-wide humidex during multi-day exposures.
The analysis of cool down assessed for a change in effect associated with a change in average daily extremes (daytime high to nighttime low humidex). During the study timeframe the range in the difference between average daily high and low humidex was 14.03 to $28.71{ }^{\circ} \mathrm{C}$, with the difference increasing as average daily maximum humidex increased. The estimated change in all age, all cause BLS calls was 0.013 per degree increase in daily humidex difference (SE 0.003), demonstrating an increasing risk of an adverse health effect with increased cooling. However, this increase is also arguable very small. It should also be noted that the average daily minimum humidex also increased as the maximum humidex increased. As a result, the increased risk demonstrated by increased cooling may be the result of higher overall temperatures rather than an increase in the difference in high to low temperatures. Future analyses should more thoroughly investigate the diurnal trends in humidex and their association with call volumes to assess whether this relationship changes under certain conditions.

\section{Discussion}

This study offers a comprehensive analysis of health conditions necessitating emergency medical services stratified by age groups. It assesses the impacts on BLS and ALS levels of care independently and contributes to the limited body of literature characterizing changes in EMS transportation volume. Moreover, this study contributes to the ongoing characterization of the effects of extreme heat on health for a region of the United States that is highly 
vulnerable to such effects [32]. It also advances the discussion about the reportedly stronger association between temperature and mortality in northern U.S. cities versus southern U.S. cities [3].

Our overall findings-an increased risk of an EMS call for all ages and all causes of $8 \%$ for BLS and $14 \%$ for ALS-demonstrate a significant effect of heat that is consistent with the 9-16\% range reported in existing EMS literature [7-9, 17, 21] and previous findings for mortality (10\% increase on a 99th percentile heat day compared with a non-heat day) within King County, WA [3]. While the observed BLS relative risk effect estimates were consistently lower than the ALS estimates, the narrower confidence intervals and larger sample sizes for the age groups and specific health conditions allows us to be more confident in the result of the BLS analysis. The higher model-selected humidex threshold for the ALS analysis (99th percentile versus 95th percentile) likely contributed to the larger effect estimates in the ALS analysis of relative risk compared with the BLS analysis. This explanation is supported by the reversal in the relative magnitude of the optimum thresholds and the reported effects in the time series analyses, where the BLS data demonstrated a $6.6 \%$ increase in risk per unit humidex increase above $40.7{ }^{\circ} \mathrm{C}$ and the ALS data demonstrated a $3.8 \%$ increase in risk per unit humidex increase above $39.7^{\circ} \mathrm{C}$.

A central finding of this study is the high frequency of increased relative risks across health conditions for the 15-44 and 45-64 year-old age groups. While consistent with the limited EMS and heat literature stratified by a similar level of age specificity $[7,16]$ and recent findings in emergency department visits $[10,15]$, these results indicate vulnerability in an age range generally considered to be relatively resilient, and for which no effect has been demonstrated in analyses of other regional healthsurveillance data $[2,11]$. Since the working-aged population comprises these two age groups, these increased risks may reflect hazards related to occupational or recreational activities, such as inadequate hydration or rest [49], or differences in risk factors, such as obesity, that affect one's ability to thermoregulate during periods of exertion [29]. We were unable to consider these potential contributors to risk in our study because the EMS data does not contain variables describing body mass or indicating whether a call was related to work or recreational activities. General differences in body size, activities, and occupations associated with gender may also be informative of the risk factors leading to increased risks in these age groups, however gender was not found to affect the relationship of heat and EMS calls.

The presence of statistically significant results in the $0-4$ and 5-14 year-old age groups is also an important finding in our study that corroborates existing literature demonstrating increased risk of morbidity, mortality, and emergency department visits in children associated with heat exposure [12, 15]. Children are commonly considered to be a vulnerable population, yet research demonstrating an association between child health and heat is limited $[9,12,15,21]$. In this study we found significant increased risks of a BLS call in 0-4 and 5-14 year-old age groups from all causes, "other medical", and heat and dehydration as well as trauma and non-trauma in the $0-4$ year-old age groups, despite the relatively small sample sizes for children. Considering how other recent studies on the effects of heat on mortality and hospitalizations in King County do not report increased risks for these age groups, our findings indicate that the effects of heat on child health may be captured at an EMS level, but not higher up in the public health system [50].

When stratified by health condition, the results revealed at least one age group at significantly increased risk for eight of the non-trauma patient type categories and three of the specific health conditions. As expected, the greatest increases in risk were attributable to heat illness and dehydration, with risks increasing by as much as $341 \%$ in BLS calls (15-44 year-old age group) and $621 \%$ in ALS calls (45-64 year-old age group) on a heat day compared with a non-heat day. All ages heat illness and dehydration calls increased by $48.5 \%$ for BLS and $48.9 \%$ for ALS calls per-unit humidex increase above their respective thresholds. These rates exceeded those reported in comparable analyses: $43 \%$ for heatstroke [20] and $29 \%$ for heat-related illness [18]. Interestingly, heat illness and dehydration were the only commonly assessed health conditions in the heat-health literature to be associated with consistent increases in risk across age groups in this study. Increases in risk for cardiovascular and respiratory illnesses, the other two commonly included categories, were not significant except in the ALS relative-risk analysis of the 15-44 year-old age group for cardiovascular events; but we identified significant health conditions previously not included in the EMS heat-health literature.

Previous studies have examined the effect of extreme heat on patients experiencing neurological conditions, diabetes, and psychological issues. Neurological conditions were assessed in an Australian study of heat-related impacts on EMS by all causes as well as cardiovascular and respiratory conditions, but statistically significant neurological results were not reported [7]. Heat was demonstrated to increase the risk of diabetic-related mortality in the 45-64 year-old age group in the Pacific Northwest-one of the age groups (along with the 65-84 year-old age group) identified in this study as being at increased risk of diabetes [2]. Increased risks of psychological conditions have also been reported in relation to 
extreme heat [51], although not for EMS calls. The remaining associations revealed in this study-abdominal/ genito-urinary, alcohol/drug, and anaphylaxis/allergy reaction-have received no mention in relevant literature.

When stratified by transport activity, this study's results revealed that the directional agreement of increases in no transportation and any transportation across age groups and analyses reflects an overall increase in calls, but no clear change in the composition of patient transportation needs. However, the relatively greater increase in the no transportation category suggests a greater proportion of the heat-related calls were treatable by EMS in the field since they did not require transportation to an Emergency Department. This finding is contrary to the $24.8 \%$ overall increase in transportation on heat days compared with non-heat days reported for EMS in Boston, Massachusetts [21]. These opposing results could be attributable to differences between the model used in this study (threshold of extreme heat) and the one used by Kue and Dyer (regionally accepted trigger for heat warnings); the inclusion of rural calls in King County versus restriction to urban calls in Boston; or regional differences in population and access to health care. In any case, EMS transportation (an activity resulting in emergency department visits) provides insight into the impact on emergency departments-a component of regional health-surveillance systems in King County that currently lacks comprehensive data.

The high optimum thresholds selected by the time series analyses introduced tension between the use of established statistical methodology and the potential integration of results into practice. The method used to select these thresholds, the Akaike Information Criterion is commonly applied in statistical analyses, but the high thresholds of $40.7{ }^{\circ} \mathrm{C}$ humidex for BLS and $39.7{ }^{\circ} \mathrm{C}$ humidex for ALS-both considerably greater than even the 99th percentile of humidex $\left(36.7{ }^{\circ} \mathrm{C}\right)$ - not only resulted in an analysis based on an extremely limited sample size but also produced risk estimates that would be applicable only a few days per year. Since these high thresholds were driven by one heat wave in 2009, expansion of the study time frame would likely attenuate them to a more relevant level for current management efforts and potential policy applications. However, thresholds of this intensity are arguably not protective of vulnerable populations or appropriate for early warning systems as they represent the most extreme exposures for this region. The researchers did investigate alternative thresholds with more promising policy and management applications by forcing the model to use the $99^{\text {th }}$ percentile $\left(36.7^{\circ} \mathrm{C}\right)$, but effect estimates were generally unchanged or slightly weakened. While the high thresholds selected by the AIC are statistically appropriate and may be indicative of future trends in extreme heat-and thus should not be completely discounted-further investigation into the most appropriate approach to setting time series thresholds should be considered to maximize both the scientific and practical applications of climate change and human health research.

\section{Strengths and limitations}

This study has several limitations. We excluded approximately $20 \%$ of records that were missing information on age or gender. This may have affected our ability to detect true increases in EMS call volume, especially when stratifying by age or call type due to diminished study power. However, a sensitivity analysis found that the associations we report for all ages and all causes would not have changed if we had included all records in the analysis.

Accurate representation of King County's EMS needs could have been influenced by the use of private ambulance services if the distribution of calls made directly to those services, and thus bypassing 911 dispatchers, caters disproportionately to particular age groups, such as those in retirement facilities. Future studies should attempt to collect data from private EMS services in addition to public services.

Misclassification of disease may have occurred as a result of inherent differences between the patient type codes used by EMS responders and the ICD codes that are the gold standard for physician diagnoses. EMS responders identify the most likely condition of concern on the basis of symptoms observed in the field with the limited time and tools available to them. Since some conditions present with similar symptoms, it is possible for the assessment of a given health condition to change in an emergency department setting, where additional diagnostic criteria may be applied. Nonetheless, the study's results are still highly applicable to public health interpretation as well as to EMS planning and preparation because they describe patients' physical states during periods of extreme heat.

The county-wide averaging of meteorological data, use of average relative humidity, and reliance solely on outdoor conditions likely introduced exposure misclassification to the analysis. The $5,480 \mathrm{~km}^{2}$ region of King County [35] includes a range of climatological, geographic, and demographic areas, such as densely populated, sealevel cities on the western edge (where the humidex tends to be slightly higher), to rural, forest-covered mountains in the east (where humidex tends to be slightly lower). Averaging conditions across these differences likely attenuated the daily maximum humidex for this County's primarily western-centered population, resulting in misclassification of calls as unexposed (type 2 errors). An alternative approach, in which each EMS call is spatially assigned to the nearest meteorological-grid center point, rather than averaging the calls across the region, should 
be considered for future research. Exposure misclassification may have resulted from the use of average relative humidity, the only available form of relative humidity in the meteorological data, in the calculation of maximum humidex. While the heat-health relationships reported in this study should not have been affected, the thresholds may be slightly inflated due to the inverse relationship of temperature and relative humidity. The inability to capture conditions that contributed to, or mitigated, individual-level exposures-including access to air conditioning or shade-may have introduced additional exposure misclassification that the data could not address.

We did not adjust for the presence of multiple comparisons in this study primarily because the nested nature of the outcome variables facilitated a staged analysis where significant impacts on all ages and all causes were identified prior to investigating specific age groups or subcategories of health. Additional justification for not adjusting the analysis is rooted in study's aim to include a hypothesis-driving component for regional planning and preparedness efforts as well as for future research into the effects of heat on health. While a Bonferroni correction would have reduced the potential for type 1 error, it may also have increased type 2 error-the presence of which eliminates the hypothesis-driving aspects of the study and has negative implications for practitioners aiming to mitigate the impacts of heat on health. Rather than shift the error type from 1 to 2 , we opted to present all study results, highlighting those associated with a small sample size ( $\leq 20$ calls) or inconsistencies.

\section{Conclusions}

This study demonstrated a positive association between extreme heat and EMS call volume in King County, WA that is consistent with the existing EMS literature and regional effects demonstrated for other health outcomes. The high frequency of age-specific effects in working aged adults (15-44 and 45-64 year-old age groups), as well as health-specific effects not previously studied in related literature (abdominal/genito-urinary, alcohol/drug, and anaphylaxis/allergy reaction), indicate that ongoing characterization of heat-related health effects and regional climate change-adaptation vulnerability should consider expanding their scope to be more comprehensive. The presence of effects in children (0-4 and 5-14 year-old age groups) not reported in other regional studies of heat on mortality and morbidity adds important insight into our understanding of how this vulnerable population is represented in the public health literature. The overall finding that increases in calls necessitating transportation as well as calls treatable on scene may provide valuable guidance for public planning and management after further investigation is completed. Future research should concentrate on the limitations of the county- and day-level exposure assessment as well as activity-based risk factors.

\section{Abbreviations \\ ALS: advanced life support; BLS: basic life support; COPD: chronic obstructive pulmonary disease; CVA: cerebrovascular accident; EMS: emergency medical} services; OBGYN: obstetrics/gynecology; TIA: transient-ischemic attack.

\section{Competing interests}

The authors report no competing interests or disclosures.

\section{Authors' contributions}

MC carried out the preparation of analysis datasets, performed the statistical analysis, prepared tables and figures, and drafted the manuscript. TBI contributed to the acquisition and general preparation of the climate data, study design, statistical analysis, and substantial manuscript revisions. BS participated in the acquisition and general preparation of EMS data and manuscript revisions. MY contributed to the study design and manuscript revisions. RF contributed to the study conception and design as well as substantial manuscript revisions. All authors contributed to interpretation of results and read and approved the final manuscript.

\section{Acknowledgments}

The authors would like to thank the University of Washington's Climate Impacts Group for providing the meteorological dataset as well as Seattle and King County's Department of Public Health Emergency Medical Services Division for providing the EMS dataset. This research was supported, in part, by funds made available through the University of Washington's Department of Environmental and Occupation Health Sciences.

\section{Author details}

${ }^{1}$ Department of Environmental and Occupational Health Sciences, School of Public Health, University of Washington, 1959 NE Pacific St., P.O. Box 237234, Seattle, WA 98195, USA. ${ }^{2}$ Emergency Medical Services Division, Seattle and King County Department of Public Health, 401 5th Ave, Suite 1200, Seattle, WA 98104, USA.

Received: 4 November 2015 Accepted: 22 January 2016 BH?

\section{References}

1. CDC, Climate and Health Program. 2010. Retrieved May 30, 2013, from http://www.cdc.gov/climateandhealth/effects/default.htm.

2. Isaksen TB, Fenske RA, Hom EK, Ren Y, Lyons H, Yost MG. Increased mortality associated with extreme-heat exposure in King Couny, Washington, 1980-2010. Int J Biometeorol. 2016:60(1):85-98.

3. Curriero FC, Heiner KS, Samet JM, Zeger SL, Strug L, Patz JA. Temperature and mortality in 11 cities of the eastern United States. Am J Epidemiol. 2002; 155:80-7.

4. Basu R, Feng WY, Ostro BD. Characterizing temperature and mortality in nine California counties. Epidemiology. 2008;19(1):138-45.

5. Medina-Ramón M, Zanobetti A, Cavanagh DP, Schwartz J. Extreme temperatures and mortality: assessing effect modification by personal characteristics and specific cause of death in a multi-city case-only analysis. Environ Health Perspect. 2006;114:1331-6.

6. Vaidyanathan A. Evaluating extreme heat event definitions: Region-specific investigation of extreme heat and heat-related mortality. In: Proceedings of the American Meteorological Society. Austin: CDC; 2013.

7. Nitschke M, Tucker GR, Hansen AL, Williams S, Zhang Y, Bi P. Impact of two recent extreme heat episodes on morbidity and mortality in Adelaide, South Australia: a case-series analysis. Environ Health. 2011;10:42.

8. Schaffer A, Muscatello D, Broome R, Corbett S, Smith W. Emergency department visits, ambulance calls, and mortality associated with an exceptional heat wave in Sydney, Australia, 2011: a time-series analysis. Environ Health. 2012;11:3.

9. Cerutti B, Tereanu C, Domenighetti G, Cantoni E, Gaia M, Bolgiani I, et al. Temperature related mortality and ambulance service interventions during the heat waves of 2003 in Ticino (Switzerland). Soz Praventivmed. 2006;51:185-93. 
10. Kingsley SL, Eliot MN, Gold J, Vanderslice RR, Wellenius GA. Current and projected heat-related morbidity and mortality in Rhode Island. Environ Health Perspect. 2015; Advanced online publication. doi:10.1289/ehp. 1408826.

11. Isaksen TB, Yost MG, Hom EK, Ren Y, Lyons H, Fenske RA. Increased hospital admissions associated with extreme-heat exposure in King County, Washington, 1990-2010. Rev Environ Health. 2015;30:51-64.

12. Knowlton K, Rotkin-Ellman M, King G, Margolis HG, Smith D, Solomon G, et al. California heat wave: Impacts on hospitalizations and emergency department visits. Environ Health Perspect. 2006;2009(117):61-7.

13. Mastrangelo G, Fedeli U, Visentin C, Milan G, Fadda E, Spolaore P. Pattern and determinants of hospitalization during heat waves: an ecologic study. BMC Public Health. 2007;7:200.

14. Hess JJ, Saha S, Luber G. Summertime acute heat illness in U.S. Emergency Departments from 2006 through 2010: analysis of a nationally representative sample. Env Heal Perspect. 2014;122:1209-16. http://dx.doi.org/10.1289/ehp. 1306796.

15. Rhea S, Ising A, Fleischauer AT, Deyneka L, Vaughan-Batten $H$, Waller A. Using near real-time morbidity data to identify heat-related illness prevention strategies in North Carolina. J Commun Health. 2012;37:495-500.

16. Turner $L R$, Connell $D$, Tong $S$. The effect of heat waves on ambulance attendances in Brisbane, Australia. Prehosp Disaster Med. 2013;28:482-7.

17. Dolney TJ, Sheridan SC. The relationship between extreme heat and ambulance response calls for the city of Toronto, Ontario, Canada. Environ Res. 2006;101:94-103.

18. Bassil KL, Cole DC, Moineddin R, Lou W, Craig AM, Schwartz B, et al. The relationship between temperature and ambulance response calls for heat-related illness in Toronto, Ontario, 2005. J Epidemiol Community Health. 2011;65:829-31.

19. Brunetti ND, Amoruso D, De Gennaro L, Dellegrottaglie G, Di Giuseppe G, Antonelli G, et al. Hot Spot: impact of July 2011 heat-wave in southern Italy (Apulia) on cardiovascular disease assessed by Emergency Medical Service and tele-medicine support. Eur Hear J. 2013;34(July 2011):P2504.

20. Ng CFS, Ueda K, Ono M, Nitta H, Takami A. Characterizing the effect of summer temperature on heatstroke-related emergency ambulance dispatches in the Kanto area of Japan. Int J Biometeorol. 2014;58:941-8.

21. Kue RC, Dyer KS. The impact of heat waves on transport volumes in an urban emergency medical services system: a retrospective review. Prehosp Disaster Med. 2013;28:610-5.

22. Hartz D, Golden JS, Sister C, Chuang WC, Brazel AJ. Climate and heat-related emergencies in Chicago, Illinois (2003-2006). Int J Biometeorol. 2012;56:71-83.

23. Golden JS, Hartz D, Brazel A, Luber G, Phelan P. A biometeorology study of climate and heat-related morbidity in Phoenix from 2001 to 2006. Int J Biometeorol. 2008;52:471-80.

24. Hartz DA, Brazel AJ, Golden JS. A comparative climate analysis of heatrelated emergency 911 dispatches: Chicago, Illinois and Phoenix, Arizona USA 2003 to 2006. Int J Biometeorol. 2013:57:669-78.

25. Intergovernmental Panel on Climate Change (IPCC). Climate Change 2014 Impacts, Adaptation, and Vulnerability. Part A: Global and Sectoral Aspects, Contribution of Working Group II to the Fifth Assessment Report of the Intergovernmental Panel on Climate Change. Cambridge, United Kingdom and New York,NY,USA: Cambridge University Press; 2014. p. 1132.

26. Luber G, Knowlton K, Balbus J, Frumkin H, Hayden M, Hess J, et al. Ch. 9: Human Health. In: Climate Change Impacts in the United States: The Third National Climate Assessment. U.S. Global Change Research Program 220256. doi:10.7930/JOPN93H5. http://nca2014.globalchange.gov/report/sectors/ human-health

27. Hess JJ, Heilpern $\mathrm{KL}$, Davis TE, Frumkin H. Climate change and emergency medicine: impacts and opportunities. Acad Emerg Med. 2009:16:782-94. doi:10.1111/j.1553-2712.2009.00469.x.

28. Alessandrini E, Zauli Sajani S, Scotto F, Miglio R, Marchesi S, Lauriola P. Emergency ambulance dispatches and apparent temperature: a time series analysis in Emilia-Romagna, Italy. Environ Res. 2011;111:1192-200. doi:10.1016/j.envres.2011.07.005.

29. Buresh R, Berg K, Noble J. Heat production and storage are positively correlated with measures of body size/composition and heart rate drift during vigorous running. Res Q Exerc Sport. 2005;76:267-74.

30. McKinnon SH, Utley RL. Heat stress: understanding factors \& measures helps SH\&E professionals take a proactive management approach. Prof Saf. 2005:50:41-7.
31. Naughton GA, Carlson JS. Reducing the risk of heat-related decrements to physical activity in young people. J Sci Med Sport. 2008;11:58-65.

32. Reid CE, O'Neill MS, Gronlund CJ, Brines SJ, Brown DG, Diez-Roux AV, et al. Mapping community determinants of heat vulnerability. Environ Health Perspect. 2009;117:1730-6.

33. Jackson JE, Yost MG, Karr C, Fitzpatrick C, Lamb BK, Chung SH, et al. Public health impacts of climate change in Washington State: projected mortality risks due to heat events and air pollution. Clim Change. 2010;102:159-86.

34. U.S. Census Bureau, Population Division. Annual Estimates of the Resident Population: April 1, 2010 to July 1, 2014. 2015. http://factfinder.census.gov/ faces/tableservices/jsf/pages/productview.xhtml?src=bkmk. Accessed 22 July 2015

35. U.S. Census Bureau. State and County QuickFacts. 2015. http://quickfacts. census.gov/qfd/states/53/53033.html. Accessed 13 July 2015.

36. Public Health Seattle King County (PHSKC) Division of EMS. Annual Report to King County Council. 2012. http://www.kingcounty.gov/healthservices/ health/ems/reports.aspx. Accessed date Apr 2013.

37. Office of Financial Management (OFM). Intercensal Estimates of April 1 Population by Age and Sex: 2000-2010. 2012. http://www.ofm.wa.gov/pop/ asr/ic/default.asp. Accessed date May 2014

38. Office of Financial Management (OFM). Postcensal Estimates of April 1 Population by Age and Sex: 2010-Present. 2013. http://www.ofm.wa.gov/ pop/asr/ic/default.asp. Accessed May 2014

39. Maurer EP, Wood AW, Adam JC, Lettenmaier DP. A long-term hydrologically based dataset of land surface fluxes and states for the conterminous United States: update and extensions. Am Meteorol Soc. 2002;15:3237-51.

40. National Oceanic and Atmospheric Administration (NOAA) Satellite and Information Service. Global Historical Climatology Network - Daily. 2009. http://www.ncdc.noaa.gov/oa/climate/ghcn-daily/. Accessed date Nov 2014.

41. Daly C, Halbleib M, Smith Jl, Gibson WP, Doggett MK, Taylor GH, et al. Physiographically sensitive mapping of climatological temperature and precipitation across the conterminous United States. Int J Climatol. 2008;28: 2031-2064.

42. Barnett AG, Tong S, Clements AC. What measure of temperature is the best predictor of mortality? Environ Res. 2010;110:604-11.

43. Canadian Centre for Occupational Health and Safety. Humidex Rating and Work. 2011. http://www.ccohs.ca/oshanswers/phys_agents/humidex.html. Accessed date Nov 2014

44. Environmental Protection Agency (EPA). Excessive Heat Events Guidebook 2006. http://www.epa.gov/heatisland/about/pdf/EHEguide_final.pdf. Accessed date May 2013

45. Schwartz J. Who is sensitive to extremes of temperature? A case-only analysis. Epidemiology. 2005;16:67-72.

46. Oracle MySQL Workbench. Computer software. Oracle. Vers. 5.2.47 Ce. 2013. http://www.oracle.com/us/products/mysql/mysql-workbench-066221.html.

47. RStudio. RStudio: Integrated development environment for R. Version 0.97 449. 2012. Boston, MA. http://www.rstudio.org/.

48. Excel for Mac 2011. Computer program. Version 14.3.6. Redmond, WA. Microsoft Corporation; 2011.

49. OSHA. Campaign to Prevent Heat IIIness in Outdoor Workers. Occupational Safety and Health Administration. 2014. https://www.osha.gov/SLTC/ heatillness/index.html. Accessed October 2014.

50. Vanos JK. Children's health and vulnerability in outdoor microclimates: a comprehensive review. Environ Int. 2015;76c:1-15.

51. Hansen A, Bi P, Nitschke M, Ryan P, Pisaniello D, Tucker G. The effect of heat waves on mental health in a temperate Australian City. Environ Health Perspect. 2008;116:1369-75. 